\title{
A EFICÁCIA DA APLICAÇÃO DA LEI DE CRIMES AMBIENTAIS PARA A PROTEÇÃO DO MEIO AMBIENTE NO LITORAL SUL DA BAHIA
}

\section{THE EFFECTIVENESS OF THE ENFORCEMENT OF ENVIRONMENTAL CRIMES FOR THE PROTECTION OF THE ENVIRONMENT IN THE SOUTH COAST OF \\ BAHIA}

\begin{abstract}
REINALDO MARTINS LEMOS
Possui graduação em Geografia pela Universidade Estadual de Santa Cruz - UESC (2005). Tem experiência na área de Geografia, com ênfase em Geografia Ambiental, Meio ambiente e Legislação Ambiental. Especialização em Educação Geoambiental pela Faculdade do Sul - FACSUL (2007) e Especialização em Biologia de Florestas Tropicais - UESC (2008) e Especialização em Direito Ambiental - UNIP (2010) e Mestre em Conservação da Biodiversidade e Desenvolvimento Sustentável pela ESCAS/IPÊ (2013). pcreinaldo@hotmail.com
\end{abstract}

\begin{abstract}
ALEXANDRE UEZU
Possui graduação em Ciências Biológicas pelo Instituto de Biociências da Universidade de São Paulo (1999) e mestrado e doutorado em Ecologia pela mesma instituição (2002 e 2007 , respectivamente). Atualmente é pesquisador do Instituto de Pesquisas Ecológicas e professor pela ESCAS - Escola Superior de Conservação Ambiental e Sustentabilidade. aleuezu@gmail.com
\end{abstract}

MARIA JOSÉ BRITO ZAKIA

Possui graduação em Engenharia Florestal pela Universidade de São Paulo (1980), Mestrado em Recursos Florestais pela Universidade de São Paulo (1986) e Doutorado em Ciências da Engenharia Ambiental pela Universidade de São

Paulo (1998). Foi Pesquisadora e Consultora do Instituto de Pesquisas e Estudos Florestais (IPEF) e da Sociedade Brasileira de Silvicultura bem como Professora Cred enciada da Pós-Graduação em Recursos Florestais pela Universidade de São Pauloaté 2006. De janeiro de 2005 a janeiro de 2009 foi funcionária da VCP , nas áreas ambiental e depois de relacionamento socioambiental. Atualmente é Consultora na área socioambiental , coordenadora técnica do PCSN ( programa de silvicultura de nativa ) do IPEf e professora convidada do PPG da UNESP - campi Guaratinguetá - Bauru.

\section{Cláudio Benedito Valladares Pádua}

Administrador de empresas e biólogo. Possui mestrado em estudos latino americanos e doutorado em ecologia pela Universidade da Flórida em Gainesville, EUA. É professor aposentado da Universidade de Brasília. Atualmente exerce a função de reitor da Escola Superior de Conservação e Sustentabilidade e Vice-Presidente do IPÊ Instituto de Pesquisas Ecológicas. Cláudio é também pesquisador associado sênior do Centro de Estudos Ambientais e de Conservação da Columbia University. Atualmente ocupa a posição sócio diretor da Biofílica SA uma empresa brasileira dedicada a transações no mercado de desmatamento evitado na Amazônia (REDD). É também membro do conselho do WWF Brasil e do Fundo Brasileiro para a Biodiversidade FUNBIO. cpadua@ipe.org.br 


\section{RESUMO}

Este trabalho buscou avaliar a efetividade da aplicação da Lei de Crimes Ambientais e o andamento dos processos administrativos e judiciais no Litoral Sul da Bahia, como forma de proteção ambiental. Esta região é de grande importância ecológica, onde possui várias Unidades de Conservação, por isso, é uma parte importante no Corredor Central da Mata Atlântica CCMA - Brasil. Foram analisados 136 autos de infrações ambientais emitidos pelo IBAMA em Ilhéus/BA, no ano de 2010, para avaliar a eficácia da aplicação da Lei de Crimes Ambientais e seu andamento, situação e duração nos processos administrativo, civil e penal. 0 presente estudo mostrou que há a necessidade de criar iniciativas para aperfeiçoar e responsabilizar os infratores para coibir ou diminuir os crimes ambientais no Litoral Sul da Bahia, com a localização e identificação dos crimes e seus responsáveis, bem como, uma maior agilidade nos processos administrativos, civis e penais, para punir os infratores e aumentar a eficácia, eficiência e efetividades dos órgãos ambientais e das Leis de Crimes Ambientais.

Palavras-chave: crime ambiental; ecologia; mata atlântica.

\begin{abstract}
This study evaluated the effectiveness of the implementation of the Environmental Crimes Law and the progress of administrative and judicial proceedings on the Litoral Sul da Bahia, as a form of environmental protection. This region is of great ecological importance, which has several protected areas, so it is an important part in the Corredor Central da Mata Atlântica - CCMA - Brazil. We analyzed 136 records of environmental violations issued by IBAMA in Ilhéus/BA, in 2010, to evaluate the effectiveness of the implementation of the Environmental Crimes and its progress, location and duration in administrative proceedings, civil and criminal. The present study showed that there is a need to create initiatives to improve and indict offenders to curb or reduce environmental crimes in Litoral Sul da Bahia, with the location and identification of crimes and their caregivers, as well as greater flexibility in administrative procedures, civil and criminal, to punish offenders and to increase the effectiveness, efficiency and investigate the effectiveness of environmental agencies and the environmental Crimes Laws.
\end{abstract}

Keywords: environmental crime; ecology; rainforest.

\section{SUMÁRIO}

INTRODUÇAO; 1. LOCALIZAÇÃO DA ÁREA DE ESTUDO; 2. CRIMES AMBIENTAIS NO LITORAL SUL DA BAHIA; 3. TIPOS DE CRIMES AMBIENTAIS; 3.1. Crimes contra a flora; 3.2. Crimes contra a fauna; 3.3. Outros crimes; 4. RESPONSABILIDADE ADMINISTRATIVA, CIVIL E PENAL NO MUNICÍPIO DE ILHÉUS, BAHIA; 4.1. Procedimento Administrativo; 4.2. Procedimento civil e penal; 5. DIAGNÓSTICO AMBIENTAL NO LTORAL SUL DA BAHIA EM 2010; CONCLUSÃO; REFERÊNCIAS.

\section{INTRODUÇÃO}

Boa parte dos biomas e ecossistemas mundiais está ameaçada devido às diversas atividades que o ser humano impôs e impõe ao meio ambiente, dentre eles destaca-se a Mata Atlântica. Este é considerado uma das áreas prioritárias (hotspots) para conservação da biodiversidade no mundo e um dos mais ameaçados do planeta ${ }^{1}$. Decorrente do avanço dos

\footnotetext{
${ }^{1}$ MYERS, N.; MITTERMEIER, R.A.; MITTERMEIER, C.G.; FONSECA, G.A.B. \& KENT, J. 2000. Biodiversity hotspots for conservation priorities. Nature 403: 853-858.
} 
maiores centros urbanos e rurais do país esse bioma foi o que mais sofreu com perdas florestais ${ }^{2}$. Desde o descobrimento do Brasil, a Mata Atlântica vive constantes degradações, desde a retirada de madeira, até os desmatamentos para o plantio e criações de animais. Hoje, encontra-se reduzida a menos de $16 \%$ da sua cobertura original e transformada em pequenos fragmentos e apenas 9\% dessa área encontra-se protegida em Unidade de Conservação - UC ${ }^{3}$.

As ameaças a Mata Atlântica acontecem desde a chegada dos portugueses ao país, em 1500, com os grandes ciclos de destruição impostos ao ecossistema, como: a exploração do paubrasil, mineração do ouro e diamantes, criação de gado e plantações de cana-de-açúcar e café, até a industrialização, exportação de madeira. Mais recente a expansão urbana desordenada aliada a expansão agrícola, pecuária e industrial, desalojam os últimos remanescentes do Bioma ${ }^{4}$.

Por sua vez, a Mata Atlântica localizada na região Sul da Bahia tem um valor físico e biológico tão relevante que no ano de 2000 passou a ser considerada "Sítio do Patrimônio Mundial Natural”, pela UNESCO, a qual, através da Fundação das Nações Unidas, tem promovido e apoiado ações voltadas a sua preservação e recuperação.

Também, por causa da grande importância ambiental do Bioma Mata Atlântica no Sul da Bahia, está sendo implementado o projeto “Corredores Ecológicos”, o qual tem como objetivo, estabelecer ligação entre as "ilhas de mata” existentes ${ }^{5}$.

Além disso, a região possui várias UC's, onde podemos destacar em nível Federal, o Parque Nacional Serra das Lontras (11.336 ha.), Refúgio de Vida Silvestre de Una (23.326 ha.), Reserva Biológica de Una (18.500 ha.), e Reserva Extrativista de Canavieiras (100.645,85 ha.) e em nível Estadual, APA Baía de Camamu (118.000 ha.), APA Itacaré - Serra Grande (62.960 ha.), APA Lagoa Encantada e Rio Almada (157.745 ha.) e o Parque Estadual Serra do Conduru (9.275 ha.). Um total de 501.787,85 ha. de UC tendo como responsável o ICMBio (Federal) e a SEMA (Estadual) para a sua fiscalização e proteção.

No período de 2000 a $2005^{6}$, a Bahia ficou entre os três estados que mais perderam cobertura vegetal, com 24.148 ha desmatados. Minas Gerais, São Paulo, Santa Catarina, Paraná

\footnotetext{
${ }^{2}$ DAL VESCO, L. L. Culturas nodulares e micropropagação de bromélias nativas da mata atlântica (Billbergia zebrina e Vriesea reitzii): bases para a conservação e propagação massal. Tese. Universidade Federal de Santa Catarina. Florianópolis, 2010. 91 p.

${ }^{3}$ RIBEIRO, M.C., METZGER, J.P., MARTENSEN, A.C., PONZONI, F.J. \& HIROTA, M.M. 2009. The Brazilian Atlantic Forest: how much is left, and how is the remaining forest distributed? Implications for conservation. Biol. Conserv. 142:1141-1153.

${ }^{4}$ ALIANCA. Aliança para a Conservação da Mata Atlântica.

${ }^{5}$ MPNUMA. Ministério Público da Bahia: Núcleo da Mata Atlântica.
} 
e Bahia são as áreas mais críticas para a Mata Atlântica, pois são os Estados que mais possuem floresta em seu território e, por isso, têm grandes áreas desmatadas em números absolutos.

Do mesmo modo, “as agressões aos remanescentes da Mata Atlântica no Litoral Sul da Bahia são graves e constantes: exploração insustentável de madeira, produção de carvão, pecuária, decadência da lavoura cacaueira, tráfico de animais silvestres, ampliação do plantio do eucalipto contribuem para a destruição do bioma"7.

Assim, uma das formas de se controlar essa destruição é através do cumprimento às legislações ambientais e fortalecimento dos órgãos de fiscalização ambiental em todos os níveis, federal, estadual e municipal, como já acontece no código de Trânsito Brasileiro. E, maior agilidade na apuração dos processos na esfera ambiental e programas de educação ambiental nas escolas em todos os níveis de ensino.

Por causa das grandes áreas com remanescentes de Mata Atlântica em toda região e de áreas prioritária na conservação ambiental (fauna e flora), surgiu à necessidade de uma análise da aplicação da Lei de Crimes Ambientais e o andamento dos processos administrativos e judiciais no Litoral Sul da Bahia, para analisar a efetividade e eficiência dos órgãos de proteção ambiental.

Este trabalho teve como objetivo avaliar a efetividade da aplicação da Lei de Crimes Ambientais e o andamento dos processos administrativos e judiciais no Litoral Sul da Bahia, identificando e classificando os crimes ambientais, onde foi elaborado um levantamento dos crimes ocorridos no ano de 2010, através dos autos de infrações do Escritório Regional do IBAMA, em Ilhéus/BA, onde foi avaliada a relação entre os crimes ambientais autuados com as evidências de degradação ambiental registradas em outras fontes de dados. Também, analisou a eficácia no andamento dos processos criminais nas esferas administrativas e civil e penal no município de maior ocorrência, no Litoral Sul da Bahia.

Para identificar e classificar os crimes ambientais foram levantados todos os 169 autos de infrações realizados em 2010 pelo Escritório Regional do IBAMA em Ilhéus/BA, sendo que, desse total, 136 foram realizados nos municípios que abrange o Litoral Sul da Bahia, um total de 80,5\% das ocorrências.

A partir do auto de infração, foi obtido o nome do autuado, CPF/CNPJ, valor da multa, descrição, tipificação, local, data, bens apreendidos e área embargada. Com isso, pode-se realizar a análise das ocorrências do ano de 2010.

${ }^{6}$ FUNDAÇÃO SOS MATA ATLÂNTICA. Portal SOS Mata Atlântica.

${ }^{7}$ MPNUMA. Ministério Público da Bahia: Núcleo da Mata Atlântica. 
Informações adicionais, como o tempo médio de duração dos processos e seu andamento na esfera administrativa, quantidade de crime e sua reincidência, pagamentos e inadimplência, foram obtidas através do Sistema de Cadastro, Arrecadação e Fiscalização - SICAFI e no Protocolo-Processos do IBAMA, sendo utilizado como entrada de busca, para pessoa física, o nome completo do infrator e o CPF, e para pessoa jurídica, razão social e CNPJ.

No $\mathrm{SICAFI}^{8}$ foram obtidos os dados sobre o município de residência do infrator, município onde ocorreu a infração e informações sobre o pagamento ou não da multa. E ainda no site do IBAMA, porém, na opção no Protocolo ${ }^{9}$, foram obtidas informações sobre a situação dos processos, como: movimentação, localização/destino, datas e despachos.

A fim de se avaliar o quanto das infrações por desmatamento identificadas corresponde de fato com aos crimes ocorridos, os dados obtidos nos autos de infração do IBAMA sobre desmatamentos por município foram comparados com as áreas desmatadas identificadas no Atlas dos Remanescentes Florestais da Mata Atlântica, período de 2008 - 2010 e o do período de 2010 2011, elaborado pela Fundação SOS Mata Atlântica e INPE ${ }^{10}$, encontrados do sítio da internet da instituição e com informações enviadas por email.

A área mapeada pela Fundação SOS Mata Atlântica e INPE abrange 10 Estados (Bahia ao Rio Grande do Sul), sendo estes, 93\% do Bioma Mata Atlântica. A interpretação foi através do visual de imagens do sensor Thematic Mapper do satélite Landsat 5 (TM/Landsat 5) e Bases cartográficas do IBGE 1:250.000. Além disso, a interpretação visual foi feita em tela de computador na escala 1:50.000 e a área mínima mapeada foi de 3 hectares ${ }^{11}$.

Informações secundárias sobre os crimes envolvendo fauna foram retiradas do $1^{\circ}$ Relatório Nacional sobre o Tráfico de Fauna Silvestre, obtidos através do sítio da internet do RENCTAS $^{12}$, com o objetivo de avaliar a relação entre os crimes ambientais autuados com as evidências registradas em outras fontes de dados.

Para analisar a eficácia no andamento dos processos criminais nas esferas administrativa, civil e penal, foi utilizado o município de maior ocorrência, no Litoral Sul da Bahia, que é Ilhéus. Como dito anteriormente, nos processos administrativos foram utilizadas informações no

\footnotetext{
${ }^{8}$ http://www.ibama.gov.br/sicafiext/

${ }^{9}$ http://Www.ibama.gov.br/protocolo/

${ }^{10}$ FUNDAÇÃO SOS MATA ATLÂNTICA. Portal SOS Mata Atlântica.

11 ATLAS. Atlas dos Remanescentes Florestais da Mata Atlântica, período 2010 - 2011. Fundação SOS Mata Atlântica e INPE. Portal SOS Mata Atlântica.

12 RENCTAS. Rede Nacional de Combate ao Tráfico de Animais Silvestres. $1^{\circ}$ Relatório Nacional sobre o Tráfico de Fauna Silvestre.
} 
Protocolo do IBAMA, e para o andamento nos processos para a análise da responsabilidade civil e penal, foram efetuadas buscas no Ministério Público Estadual.

\section{LOCALIZAÇÃO DA ÁREA DE ESTUDO}

O Território de Identidade 05, Litoral Sul, está localizado no Sul da Bahia, abrangendo 27 Municípios $^{13}$, sendo os principais Municípios, Ithéus e Itabuna. O Litoral Sul possui uma população total de 795.781 habitantes, de acordo com o censo de $2010^{14}$.

A Mata Atlântica localizada no Sul da Bahia conserva ainda uma grande diversidade de espécies na fauna, onde recentemente um novo gênero de aves (Acrobartonis fonsecae) foi descoberto em suas florestas. Além disso, o mico-leão-de-cara-dourada (Leontophitecus chrysomelas) e o macaco-prego-do-peito-amarelo (Cebus apella xanthosternos) são espécies endêmicas dessa região, ou seja, não são encontradas em nenhum outro lugar do mundo ${ }^{15}$. Além disso $^{16}$, o Sul da Bahia é considerado centro de endemismo para plantas, borboletas, sapos, aves e mamíferos (primatas e roedores).

Dentre as Unidades de Conservação, pode-se destacar o Parque Estadual Serra do Condurú - PESC, em que um estudo realizado, apontou a maior concentração de espécies arbóreas do planeta, onde, em um só hectare foram encontradas 454 espécies de árvores diferentes ${ }^{17}$.

\section{CRIMES AMBIENTAIS NO LITORAL SUL DA BAHIA}

No ano de 2010 foram registrados 136 autos de infrações pelo IBAMA de Ilhéus, uma média de 11,33 autos por mês, dentre eles, $77 \%$ foram de pessoas físicas e $23 \%$ de pessoas jurídicas. Nesse período foram aplicadas $\mathrm{R} \$ 1$ 1.433.700,00 em multas, em que o valor das multas

\footnotetext{
${ }^{13}$ SEI. Superintendência de Estudos Sociais e Econômicos.

14 IBGE. Instituto Brasileiro de Geografia e Estatística.

${ }^{15}$ ARAÚJO, M. et. al. A Mata Atlântica do Sul da Bahia: situação atual, ações e perspectivas. Série Estados e Regiões da RBMA, Caderno 8. São Paulo, 1998.

${ }^{16}$ FARIA, D. A fauna na paisagem cacaueira do Sul da Bahia.

17 MMA. Ministério do Meio Ambiente. Mata Atlântica: patrimônio nacional dos brasileiros. Secretaria de Biodiversidade e Florestas. Núcleo Mata Atlântica e Pampa; organizadores Maura Campanili [e] Wigold Bertoldo Schaffer. - Brasília, 2010.
} 
varia de $\mathrm{R} \$ 50,00$ a $\mathrm{R} \$ 150.000,00$, levando em conta a gravidade do fato, os antecedentes do infrator e a situação econômica do infrator ${ }^{18}$.

Neste ano, 55\% dos autuados, cometeram uma infração ambiental e $8 \%$ mais de uma infração ambiental, ou seja, 63\% dos autuados cometeram infração ambiental pela primeira vez em 2010; 26\% cometeram uma infração ambiental em 2010 e outros em anos anteriores e 11\% cometeram mais de uma infração ambiental em 2010 e em outros anos anteriores, ou seja, 37\% foram autuados em 2010 e em anos anteriores, o que pode gerar um agravamento no andamento do Processo Administrativo por causa da reincidência.

Em 136 autos de infrações emitidos em 2010, 65\% dos autuados residem no próprio município onde ocorreu o auto de infração e 35\% não residiam no município onde ocorreu o crime. Dos $65 \%$ autuados residentes no mesmo município onde ocorreu o crime, $71 \%$ foram autuados em crimes contra a flora, $7 \%$ fauna, $22 \%$ em outros crimes ambientais, como atividade ambiental sem licença, construção em APA sem autorização do órgão competente e em solo não edificável.

$\mathrm{Na}$ identificação dos tipos das infrações em relação ao município de origem, semelhança nos altos índices de crimes contra a Flora (depósito e/ou transporte de madeira serrada sem autorização dos órgãos competentes), em todos os casos, residentes em outros municípios e no mesmo município de residência, os valores estão entre $71 \%$ a $87 \%$. Seguindo os mesmos parâmetros estão os crimes contra a Fauna, 5\% a 7\% e outros crimes, entre 13\% a 22\%.

\section{TIPOS DE CRIMES AMBIENTAIS}

Dos 136 autos de infração no Litoral Sul da Bahia em 2010, 73\% foram contra a flora; 6\% contra a fauna; e $21 \%$ outros crimes ambientais. 0 maior número das ocorrências foi relacionado com crimes contra a flora, onde estão incluídos os desmatamentos, os cortes seletivos sem autorização, depósito e transporte de madeira e carvão sem a documentação prevista em lei, construção em APA sem autorização, impedir ou dificultar regeneração, explorar vegetação e danificar vegetação.

${ }^{18}$ Art. $6^{\circ}$, Lei $\mathrm{n}^{\circ} 9.605 / 98$. 


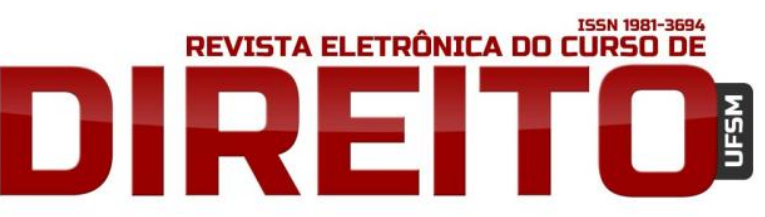

A EFICÁCIA DA APLICAÇÃO DA LEI DE CRIMES AMBIENTAIS PARA A PROTEÇÃO DO MEIO AMBIENTE NO LITORAL SUL DA BAHIA

REINALDO MARTINS Lemos / ALEXANDRE UEzU / MARIA JosÉ BRITo ZaKIA / CLÁUdio BENEDITO VAlladares PÁdUa

\subsection{Crimes contra a flora}

Dos crimes contra a flora, 43\% das ocorrências, estão relacionadas com madeira serrada sem a comprovação de origem, sendo $81 \%$ dos autos de infração lavrados contra depósito e $19 \%$ no transporte. Nesse período foram retirados das matas 627,59 metros cúbicos de madeira de diversas espécies. Já os cortes de árvores contribuem com $12 \%$ dos crimes contra a flora, onde foram retiradas 367 árvores sem a devida autorização.

Em segundo lugar, com $25 \%$ das ocorrências, estão os desmatamentos, em 83,0223 hectares distribuídos em 12 municípios, onde podemos destacar o Município de Santa Luzia, 37,48 ha, seguidos de Coaraci, Maraú, Jussari e Ilhéus.

Não foi possível identificar o local exato do auto de infração referente aos desmatamentos no ano de 2010, em virtude de alguns autos não apresentarem as coordenadas geográficas do local e outros com dúvidas na caligrafia. Apenas sendo possível identificar o município onde ocorreu a infração.

Ao comparar os desmatamentos identificados por meio dos autos de infração com os dados de desmatamentos disponibilizados no Atlas da Mata Atlântica verificou-se que há uma diferença entre o registrado pelo IBAMA e o identificado pelo Atlas, como por exemplo, 0 município de Canavieiras. Onde foram identificados pelo EREG do IBAMA 1,82 hectares desmatados e pela Fundação SOS Mata Atlântica/INPE ${ }^{19}$ foram identificados 1.337 hectares.

Além de Canavieiras, outros municípios no Litoral Sul da Bahia tiveram diferenças significativas entre os desmatamentos identificados pelo IBAMA e os desmatamentos identificados pela Fundação SOS Mata Atlântica/INPE, entre eles podemos destacar os municípios de Santa Luzia, Una e Mascote.

\subsection{Crimes contra a fauna}

Dos 6\% dos autos de infração emitidos pelo EREG do IBAMA em Ilhéus relacionados com os crimes contra a fauna, 38\% foram devido à manutenção de animal silvestre em cativeiro sem autorização do órgão competente, com vinte e um animais recuperados (três jabutis e dezoito aves) e encaminhados ao CETAS em Vitória da Conquista/BA para cuidados de biólogos/veterinários e reabilitados/reintegrados ao meio ambiente natural.

${ }^{19}$ FUNDAÇÃO SOS MATA ATLÂNTICA. Portal SOS Mata Atlântica. 
A maior parte das ocorrências, 62\% dos autos de infrações, está relacionada com a pesca e/ou comercialização no período de defeso, sendo apreendidos 1.259 unidades de caranguejo e 94 quilos de lagostas.

Nos crimes contra a fauna ${ }^{20}$, o Sul da Bahia contribui com o tráfico de animais silvestres como região de captura e também, por causa da rodovia BR-101, no transporte de animais silvestres, ligando o nordeste aos grandes centros como, Rio de Janeiro, São Paulo e Belo Horizonte, para o comércio local e exportação. No período de 1992 a 2000, foram apreendidos no nordeste, 108.041 animais silvestres. Uma média de 13.505 animais por ano em todo o nordeste.

Os animais são transportados em caminhões e carros particulares e em péssimas condições, onde 1 em cada 10 sobrevivem e às margens da BR-101, na Bahia, micos, papagaios e periquitos são vendidos por valores entre $\mathrm{R} \$ 50,00$ e $\mathrm{R} \$ 100,00^{21}$.

\subsection{Outros crimes}

Outros crimes ambientais identificados nesse trabalho estão os crimes de poluição; contra o ordenamento urbano e o patrimônio cultural e os crimes contra a administração pública.

Nesses casos, os autos de infração estão relacionados com: 8 por funcionar atividade ambiental sem licença ambiental ou autorização dos órgãos competentes; 6 por extração clandestina de minerais (areia); 5 por Construção em área de APP; 3 por construir em solo não edificável; 2 por conceder licença ambiental sem conformidade com a legislação; 1 por dificultar o acesso à praia; 1 pela falta de registro no CTF; 1 por instalar atividade potencialmente poluidora sem licença ambiental; 1 por lançar resíduos sólidos (lixo) às margens da rodovia; e 1 por lançar substância oleosa na rede pública em desacordo com a legislação.

\section{RESPONSABILIDADE ADMINISTRATIVA, CIVIL E PENAL NO MUNICÍPIO DE ILHÉUS, BAHIA}

Em 2010, o Município que teve o maior número de autos de infração foi Ilhéus, com 34 ocorrências, $25 \%$ do total das ocorrências. Nesse total, $56 \%$ foram para pessoas físicas e $44 \%$ para pessoas jurídicas. Nesse período foram aplicadas $\mathrm{R} \$ 478.900,00$ em multas, onde o valor das

\footnotetext{
${ }^{20}$ RENCTAS. Rede Nacional de Combate ao Tráfico de Animais Silvestres. $1^{\circ}$ Relatório Nacional sobre o Tráfico de Fauna Silvestre.

${ }^{21}$ Ibidem.
} 


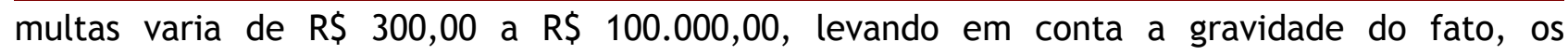
antecedentes do infrator e a situação econômica do infrator ${ }^{22}$.

O maior número das ocorrências foi relacionado com crimes contra a flora (68\%), e $3 \%$ contra a fauna e $29 \%$ com outros crimes.

\subsection{Procedimento Administrativo}

Um dos problemas encontrados no IBAMA foi à agilidade na apuração dos processos administrativos $^{23}$. Dos Processos Administrativos abertos pelo EREG/IBAMA/Ilhéus, 94\% estão em andamento e encontram-se: 17 em Eunápolis, 13 em Ilhéus, 2 em Salvador. Com relação aos processos administrativos 6\% não foram encontrados nenhuma informação sobre a instauração e o andamento.

Em média, os processos ficam 57 dias (21 - 183) em Salvador, 154 dias (1 - 496) em Ilhéus e 277 dias (1- 691) em Eunápolis. Ao todo, o Processo Administrativo do IBAMA está em média 392 dias em andamento, variando de 22 a 768 dias.

De acordo com a análise no SICAFI e com informações obtidas junto ao EREG Ilhéus, todos os procedimentos administrativos iniciados com as autuações lavradas em 2010 no município de Ilhéus, estão em andamento ${ }^{24}$.

Dos 34 autos de infrações emitidos em 2010, 13 foram acompanhados pelo auto de apreensão e depósito e 24 pelo auto de embargo. Entre os autos de apreensão, 7 dos autuados foram os responsáveis em guardar os produtos no local da apreensão até decisão judicial (35,523 $\mathrm{m}^{3}$ de madeira, 4 veículos e 5 animais silvestres). Nas áreas embargadas, podemos destacas: 7 foram por desmatamento, 5 depósito de madeira, 4 por corte seletivo, 3 extração de areia sem licença ambiental.

\subsection{Procedimento civil e penal}

Para cada auto de infração gerado pelo IBAMA de llhéus, uma cópia é encaminhada a GEREX do IBAMA em Eunápolis para ser cadastrado no sistema e aberto o processo administrativo. Após o cadastro do infrator no sistema, a GEREX de Eunápolis encaminha uma

\footnotetext{
${ }^{22}$ Art. $6^{\circ}$, Lei ${ }^{\circ} 9.605 / 98$.

${ }^{23}$ TCU. Tribunal de Contas da União. TC 022.631/2009-0.

${ }^{24}$ Informações obtidas em julho de 2012.
} 
cópia do auto de infração e informações adicionais sobre a ocorrência, para o MP local para abertura de processo civil e criminal.

Após receber as informações vindas do IBAMA, o Ministério Público Estadual tem um prazo para oferecer a denúncia ${ }^{25}$. Com relação aos crimes ambientais e em função das penas, a prescrição ocorre entre 4 e 8 anos, antes de transitar em julgado a sentença.

Em 2010, foram encaminhados 34 autos de infrações para o MP de lthéus para apurar a responsabilidade civil e penal, como prevê o Art. $3^{\circ}$ da Lei $\mathrm{n}^{\circ}$ 9.605/98. Na $11^{\text {a }}$ Promotoria de Justiça de Ithéus, Núcleo de Meio Ambiente, foram firmados 10 Termos de Ajuste e Conduta e instaurados 7 Ações Civil Publica, 10 Inquéritos Civil e 7 ocorrências não foram encontrados.

\section{a) Termo de Ajuste e Conduta - TAC}

Foram os que tiveram maior agilidade no andamento processual, sendo estes firmados 10 TAC's em um período máximo de dois anos, onde a decisão foi 100\% em prestação pecuniária, sendo 9 destinados a OSCIP's e 1 ao Fundo Municipal de Meio Ambiente.

Dos TAC's firmados, 6 foram referentes ao depósito de madeira sem comprovação de origem; 1 no transporte de madeira sem comprovação de origem, 1 por lançar substâncias in natura ao meio ambiente; 1 por cortar árvores sem autorização e 1 por realizar extração de minerais sem autorização ou licença ambiental.

\section{b) Ação Civil Pública - ACP}

Foram instauradas 7 ACP's pelos seguintes motivos: o autuado não compareceu ou não foi encontrado. Os autos de infrações que deram origem as essa ações foram: 2 por conceder licença ambiental em desacordo com a legislação vigente, 1 por desmatamento, uma por impedir ou dificultar a regeneração natural, 1 por extração de minerais sem autorização ou licença ambiental, 1 por cortar árvores sem autorização e 1 por ter animal silvestre em cativeiro sem autorização do órgão competente.

${ }^{25}$ Art. 109 do Decreto-Lei ${ }^{\circ} 2.848$, de 7 de dezembro de 1940. 
c) Inquérito Civil - IC

Foram instaurados 10 IC's para identificar a autoria do delito, aprofundar mais as informações e/ou quantificar e analisar os danos ambientais nos procedimentos. Desse total, 3 estão relacionados com desmatamento, 2 por ter em depósito madeira sem comprovação de origem, 2 por transportar madeira sem comprovação de origem, 2 por impedir a regeneração natural da vegetação e 1 por cortar árvores sem autorização do órgão competente.

Todos os procedimentos estão em andamentos e após a conclusão, o MP Estadual remeterá ao Poder Judiciário para a instrução e julgamento. Ficando o mesmo a cargo de o Judiciário marcar as audiências e andamento processual.

\section{d) Outros}

Não foram encontradas 7 ocorrências, sendo, 4 por depósito de madeira sem comprovação de origem, 1 por exercer atividade ambiental sem autorização ou licença ambiental, 1 por ter construção em solo não edificável e 1 por cortar árvores sem autorização do órgão competente.

Esses procedimentos não foram encontrados no MP de Ilhéus ou não foram enviados por vários motivos. As mais prováveis são: cópias não ficarem legíveis, dúvidas por causa da caligrafia do agente e documentos ou endereços incorretos.

\section{DIAGNÓSTICO AMBIENTAL NO LTORAL SUL DA BAHIA EM 2010}

Em 2010 foram registrados 136 autos de infrações pelo IBAMA de Ilhéus, sendo aplicado um total de R\$1.433.700,00 em multas, onde, o maior número de ocorrências, em todos os casos analisados, foram os crimes contra a flora, onde neles estão incluídos, os desmatamentos, cortes seletivos sem autorização e o transporte e depósito de madeiras sem autorização.

Neste mesmo ano, 55\% cometeram apenas um crime ambiental e $45 \%$ são reincidentes porque cometeram mais de um crime ambiental no mesmo ano ou em ano anteriores. 0 que seria um agravamento no andamento do Processo Administrativo e/ou Criminal. 
Os Processos Administrativos são demorados, onde, um auto de infração emitido em Ithéus, passa por Salvador e Eunápolis durante registro, análise e conclusão. Em 2009, o TCU²6 emitiu um "Relatório de Alerta" em relação aos processos com risco de prescrição. Com a demora na apuração, as multas aplicadas deixam de ser arrecadadas.

O IBAMA $^{27}$ relacionou um conjunto de problemas que afetam o desempenho da arrecadação de suas multas, entre eles, falha na lavratura dos autos, deficiência do sistema de cobrança e arrecadação, acúmulo de trabalho e atrasos nos processos, estruturação das áreas de arrecadação e cobrança, treinamentos constantes e o elevado número de recursos administrativos.

Um modelo eficiente no Brasil é o Sistema Nacional de Trânsito, onde cada veículo tem um registro/cadastro e qualquer auto de infração que venha cometer em qualquer parte do território nacional, ele é prontamente lançado nesse cadastro. Esse auto de infração pode ser emitido pela Polícia Rodoviária Federal (Federal), Polícia Militar (Estadual) ou Secretarias Municipais de Trânsitos (Município) e prontamente é lançado no cadastro do veículo.

$\mathrm{Na}$ renovação do documento, o proprietário do veículo é obrigado a pagar, juntamente com as taxas anuais para pegar a documentação de utilização, caso contrário, o veículo não poderá ser utilizado em via pública e sujeito a novas sanções. No caso de venda do veículo, a (s) infração (ões) estará no cadastro.

De acordo o Código de Trânsito Brasileiro ${ }^{28}$, o órgão responsável pela autuação tem até 30 dias para expedir a autuação, caso não seja expedida o auto, este será considerado nulo (Art. 281, II). Além disso, o auto de infração de trânsito remetido deverá conter, entre outras informações, a data máxima para o autuado interpor recurso (Art. 282) ou pagar o auto de infração com desconto (Art. 284). Entrando com a defesa no tempo previsto, o órgão de trânsito que impôs a penalidade deverá julgá-lo em até 30 dias (Art. 285), onde o recurso não for julgado nesse período, poderá ter efeito suspensivo (Art. 285, § $3^{\circ}$ ).

Se houvesse um sistema eficaz na apuração e cobrança dos autos emitidos pelos órgãos ambientais, bem como, nas penas impostas aos infratores, como já acontece no Sistema Nacional de Trânsito, seria uma possibilidade de coibir os crimes ambientais, principalmente em áreas de grande importância ambiental para o planeta. Com essas falhas, o Governo deixa de arrecadar uma cifra muito alta aos cofres públicos.

\footnotetext{
${ }^{26}$ TCU. Tribunal de Contas da União. TC 022.631/2009-0.

27 Ibidem.

${ }^{28}$ LEI N ${ }^{\circ} 9.605$, de 12 de fevereiro de 1998.
} 
Recentemente para agilizar e normatizar os processos administrativos do IBAMA foi publicada uma Instrução Normativa ${ }^{29}$, onde regula os procedimentos para apuração de infrações administrativas por condutas e atividades lesivas ao meio ambiente, onde podemos destacar os critérios para aplicação das sanções pecuniárias e os valores máximos e mínimos de cada infração.

Também, o IBAMA desenvolveu uma metodologia mais eficiente no andamento dos processos administrativos em Ithéus, onde o auto de infração emitido pelo EREG do IBAMA de Ilhéus se desloca até a GEREX do IBAMA em Eunápolis para registro/protocolo e retorna para a Unidade de Ilhéus, onde está funcionando o SICAFI, EQT e a Unidade Julgadora das defesas e penalidades. Nesse caso, Ithéus está funcionando com primeira estância julgadora, Salvador a segunda e em Brasília com a terceira e última estância julgadora, se couber recurso.

Porém, toda essa metodologia aplicada pelo órgão ambiental, não tem sido tão eficiente na apuração dos processos administrativos, em comparação às infrações de trânsito. De acordo a legislação vigente, um auto de infração emitido pelo IBAMA pode ficar em aberto até 3 anos sem movimentação ou em 5 anos no processo em movimentação até que se tenha uma solução ou prescrição e, os autos de infração de trânsito, juntando todos os recursos disponíveis pelo autuado, não ultrapassam de 1 ano.

A aplicação da lei de crimes ambientais no setor florestal do Pará não tem sido eficiente na proteção da flora, já que apenas $2 \%$ das multas foram pagas e $2 \%$ dos processos judiciais foram concluídos $^{30}$. Já no Litoral Sul da Bahia, 76\% dos infratores possui um "nada consta”, onde o seu processo ainda não foi analisado ou resolvido com o pagamento da multa e $24 \%$ tem registro no IBAMA referente a autos de infração anteriores a 2010.

Esse "nada consta" no sistema do IBAMA, serve para pessoas que não possuam processos administrativos, como também, para pessoas que respondam a um ou vários processos administrativos, com isso, nenhum efeito punitivo ou empecilho na sua atividade diária, como empréstimos, DOF, CTF, etc. Essa metodologia implantada pelo IBAMA pouco serve para coibir possíveis transações ambientais, como acontece nos antecedentes criminais.

A maior incidência de crimes ambientais no Litoral Sul da Bahia em 2010 está relacionada com crimes contra a flora, onde o maior número das ocorrências está relacionado com depósito de madeiras sem comprovação de origem, onde foi apreendido mais de 510 metros cúbicos de

\footnotetext{
${ }^{29}$ Instrução Normativa IBAMA n ${ }^{\circ}$ 10, de 7 de dezembro de 2012.

${ }^{30}$ BRITO, B.; BARRETO, P. Sugestões para a aplicação da Lei de Crimes Ambientais no setor florestal da Amazônia. Revista de Direitos Difusos, Ano VI, V. 30, 2005.
} 
madeiras em depósitos, o que mostra que o IBAMA foi mais eficiente em fiscalizar. Já no Estado do Pará, entre 1999 - 2002, a maior incidência foi no transporte de madeira ${ }^{31}$.

Em segundo lugar, estão os desmatamentos, com 83,0223 hectares desmatados em corte raso, distribuídos em 12 municípios. Mesmo estando em segundo lugar nas incidências de autos, os desmatamentos são poucos identificados, uma vez que, nos resultados apresentados há uma grande diferença entre os crimes ambientais encontrados com o verificado a partir de outras fontes, principalmente nos crimes contra a flora. Em comparação com os dados da Fundação SOS Mata Atlântica/INPE ${ }^{32}$ observamos que boa parte dos desmatamentos do Litoral Sul da Bahia não são autuados ou identificados.

O nível de identificação dos desmatamentos ilegais no Sul da Bahia é baixo e acontece muito tempo após o fato e muitas vezes não consegue identificar o responsável por vários motivos, entre eles: por causa do baixo interesse das pessoas em denunciar os crimes ambientais, por falta de confiança no sistema, por falta de qualificação dos agentes ou a falta de incentivo para desempenhar suas tarefas de modo mais eficiente ${ }^{33}$.

Nos anos de 2010 e 2011 foram desmatados no Brasil 13.312 hectares de Mata Atlântica ${ }^{34}$. Desse total, a Bahia ficou em $2^{\circ}$ lugar, com 4.339 hectares. Neste mesmo ano, foram identificados pela Fundação SOS Mata Atlântica/INPE 1.477 ha, nos Municípios de Canavieiras, Santa Luzia, Una e Mascote.

Nesses dados, podemos destacar o Município de Canavieiras, onde o IBAMA encontrou 1,82 hectares de desmatamento, enquanto a Fundação SOS Mata Atlântica/INPE encontrou 1.337 hectares de desmatamento, sendo considerado o $2^{\circ}$ maior município do Brasil em desmatamento. Pode-se observar que falta um modelo mais eficaz para o IBAMA monitorar os desmatamentos e identificar os infratores, para poder apurar e coibir essa prática, onde, essas áreas podem estar sendo transformadas em agricultura, pecuária, entre outros.

Já no município de Una, dos 45 hectares detectados pela Fundação SOS Mata Atlântica/INPE, 17 hectares estão na Reserva Biológica e 12 hectares no Refúgio da Vida Silvestre, ambas, UCs Federal e de responsabilidade do ICMBio. Como se pode notar, assim como

\footnotetext{
${ }^{31}$ BRITO, B.; BARRETO, P. Sugestões para a aplicação da Lei de Crimes Ambientais no setor florestal da Amazônia. Revista de Direitos Difusos, Ano VI, V. 30, 2005.

${ }^{32}$ FUNDAÇÃO SOS MATA ATLÂNTICA. Portal SOS Mata Atlântica.

${ }^{33}$ AKELLA, A. S.; ORLANDO, H.; ARAÚJO, M.; CANNON, J. B. O fortalecimento da defesa contra crimes ambientais: análise econômica do sistema de implementação legal na Mata Atlântica do Brasil. Megadiversidade. V. 2. $\mathrm{n}^{\circ}$ 1-2, 2006.

${ }^{34}$ FUNDAÇÃO SOS MATA ATLÂNTICA. Portal SOS Mata Atlântica.
} 
o IBAMA, o ICMBio necessita de um modelo mais eficaz para monitorar os desmatamentos nas UCs Federais.

Os dados apontam que o IBAMA não está equipado e/ou preparado para combater os crimes contra a fauna por causa da baixa quantidade de ocorrência durante o ano. Podemos observar que os crimes contra a fauna foram detectados nos meses de fevereiro, maio, junho e novembro, ao contrário dos crimes contra a flora, que foram detectados durante todo o ano.

Entre os crimes contra a fauna, 62 \% estão relacionados com crimes por pescar em período do defeso, onde foram apreendidos 1.259 caranguejos e 94 quilos de lagosta. Os outros $38 \%$ estão relacionados com animais silvestres em cativeiro, onde foram feitos três autos de infração e apreensão de animais em cativeiro, onde 21 animais foram recuperados, sendo três jabutis e 18 aves e encaminhados para o CETAS em Vitória da Conquista para serem reabilitados. Um número bastante pequeno se comparados com o total de apreensões em todo o nordeste em 2000, que foram o de 9.803 animais $^{35}$.

Nos crimes contra a fauna, o número é baixo, apesar do Relatório do RENCTAS indicar a região como captura e transporte de animal silvestre, grandes áreas de remanescentes de mata atlântica preservada e várias Unidades de Conservação (Federal, Estadual, Municipal e Particular). Também, na região há a cultura de criar animais silvestres em cativeiro, principalmente as aves.

Os números revelam que há uma carência de fiscalização e combate ao tráfico de animais silvestres e em cativeiro, onde as principais dificuldades no combate ao tráfico de animais silvestres no Brasil é a falta de contingente, veículo, equipamentos, lugar para destinar animais apreendidos $^{36}$.

Apesar dos números apontarem uma demanda maior no combate aos crimes contra a fauna, esse número pequeno de apreensões de animais podem estar diretamente relacionados com a falta de contingente e veículo, bem como, um local mais apropriado para deixar os animais na região, uma vez que, o CETAS mais próximo fica localizado em Porto Seguro, distante de Ilhéus aproximadamente $263 \mathrm{~km}$. Além disso, transportar animais requer mais cuidados, técnicas específicas e recursos.

Os crimes relacionados com extração de minerais sem autorização ou em desacordo com a obtida aparecem com uma quantidade expressiva. Essa prática constituiu na retirada da

\footnotetext{
${ }^{35}$ RENCTAS. Rede Nacional de Combate ao Tráfico de Animais Silvestres. $1^{\circ}$ Relatório Nacional sobre o Tráfico de Fauna Silvestre.

${ }^{36}$ Ibidem.
} 
cobertura vegetal, mudança do relevo e transporte de materiais, onde, muitas vezes, afugentam a fauna local e danificam os recursos hídricos. Também, na região possui muitas áreas de proteção ambiental, por isso, existem ocorrências em relação de construção em área de APA sem autorização ou licença ambiental do órgão competente.

Em 2010, o Município que teve a maior incidência de crimes ambientais foi o Município de Ilhéus, com $25 \%$ das ocorrências. Nesse período foram lavrados 34 autos de infração e aplicados R\$ 478.900,00 em multas. Também, neste caso, o maior número de ocorrências está relacionado com crimes contra a flora.

O $\mathrm{TCU}^{37}$ já identificou problemas na apuração dos processos administrativos e na arrecadação em todo o Brasil, em Ilhéus, não poderia ser diferente. Há dificuldade no andamento dos processos administrativos registrados em 2010, onde os autos de infração são registrados em Salvador e logo em seguida encaminhados para llhéus, sendo esses, concluídos na GEREX do IBAMA em Eunápolis. Com isso, muito tempo de tramitação em setores e Municípios.

De acordo com o Art. $21^{38}$, prescreve com cinco anos os processos administrativos do IBAMA, contados a partir do dia da lavratura do auto de infração. Dessa forma, último levantamento realizado em junho de 2012, com os autuados em 2010 pelo IBAMA em Ilhéus, todos os processos administrativos levantados neste trabalho podem prescrever em 2015.

Além disso, no $\$ 2^{\circ}$ do mesmo Decreto, incide na prescrição se a apuração ficar parada por mais de três anos. Nesse caso, 21\% dos processos administrativos instaurados, prescreverão em 2013 e 24\% em 2014, caso permaneçam parados.

Em Ithéus, dos 94\% dos processos administrativos que estão em andamento, 76\% não possuem nenhuma restrição, ou seja, o seu processo ainda não foi analisado, foi arquivado por causa de algum recurso/defesa ou foi resolvido com o pagamento da multa. Esses processos estão em andamento em média, 392 dias, variando de 22 a 768 dias.

Os processos administrativos são lentos e a ineficácia é por causa da insuficiência de recursos humanos, incidência de erros dos autos de infração e de erros processuais, ausência de TAC, índices de defesa, inadimplência nos parcelamentos, poucos casos em dívida ativa e em cobrança judicial $^{39}$.

\footnotetext{
${ }^{37}$ TCU. Tribunal de Contas da União. TC 022.631/2009-0.

${ }^{38}$ DECRETO $N^{\circ}$ 6.514, de 22 de junho de 2008.

${ }^{39}$ BRITO, B.; BARRETO, P. Sugestões para a aplicação da Lei de Crimes Ambientais no setor florestal da Amazônia. Revista de Direitos Difusos, Ano VI, V. 30, 2005.
} 
Também, o nível de arrecadação nos processos administrativos é baixo, por causa das contestações judiciais dos autos, pela inadimplência dos pagamentos das multas parceladas, pela demora entre as fases intermediárias de cobrança e pela ineficácia dos meios de cobrança ${ }^{40}$.

Além dos problemas apontados no andamento dos processos administrativos em Ilhéus, os dados apontam uma situação nos produtos apreendidos, onde as madeiras e veículos ficam com os autuados. No caso da madeira em um depósito de uma madeireira ou carpintaria, ela serve para legitimar um produto apreendido, onde pode ser comercializada e sempre repondo o produto ilegal no pátio para a venda, ou seja, certa quantidade de madeira no pátio serve para o comércio e em uma nova fiscalização é apresentado à madeira aprendida. Além disso, os veículos com os autuados podem servir novamente para outro ilícito, uma vez que, continuam em posse do infrator.

Pelo acordo firmado, cada auto de infração do IBAMA, uma cópia é encaminhada ao MP mais próximo do local da infração. Neste caso, o MP de Ilhéus, no ano de 2010, recebeu 34 autos de infração para abertura de ação criminal.

Os dados coletados nos municípios de Ilhéus, Itabuna e Una apontam ineficiência no encaminhamento das cópias dos autos, onde em setembro de 2001, o Ministério Público de Itabuna, recebia os autos de infrações dos anos de 1991, 1992 e 1994. Dados apontam uma maior agilidade nos autos de infrações emitidos pelo IBAMA em 2010, onde 79\% dos autos emitidos no município de llhéus encontram-se registrados do MP e desses, $29 \%$ concluídos $^{41}$.

Existem vários motivos pelos quais os processos estão mais rápidos, como, a criação do MP Ambiental, informatização, agilidade, concurso, funcionário na área ou cumprimento de normas e padrões, visto que, essa demora e dificuldades já foram apontadas.

Dos 34 autos de infração recebidos pelo MP de Ilhéus, 10 se tornaram TAC's, 7 ACP's, 10 IC's e 7 autos não foram encontrados ou não foram enviados. As causas mais prováveis de não terem recebidas foram por causas das cópias não ficara ilegíveis, duvidas na caligrafia do agente e documentos ou endereços incorretos, problemas estes, já identificados pelo $\mathrm{TCU}^{42}$ em todo o Brasil.

\footnotetext{
40 Ibidem.

41 AKELLA, A. S.; ORLANDO, H.; ARAÚJO, M.; CANNON, J. B. O fortalecimento da defesa contra crimes ambientais: análise econômica do sistema de implementação legal na Mata Atlântica do Brasil. Megadiversidade. V. 2. $\mathrm{n}^{\circ}$ 1-2, 2006.

42 TCU. Tribunal de Contas da União. TC 022.631/2009-0.
} 
Os TAC's foram os que tiveram a maior agilidade, sendo $100 \%$ em prestação pecuniária, onde 90\% destinados a OSCIP's e 10\% ao Fundo Municipal de Meio Ambiente, porém, não se sabe se os termos firmados são aplicados diretamente para projetos relacionados com a proteção ou recuperação do meio ambiente natural.

O Ministério Público Estadual deveria analisar as formas que são realizados os TAC's, onde crimes graves contra o meio ambiente não poderiam ser firmados e sim ações mais severas, de acordo ao dano ambiental causado e sua reparação. Apesar de penas pecuniárias pesarem no bolso do infrator, estes dificilmente retornam ao meio ambiente natural e aos problemas por ele causados.

Crimes como desmatamento, extração de madeira, atividade sem licença ou autorização ambiental, entre outros, deveriam ser punidos com prestação pecuniária, bem como, reparação de todo o dano ambiental.

A maioria das propostas analisadas de transação penal na cidade de Belém do Pará/PA, visou à assistência social, incluindo a doação de alimentos e roupas, nos processos iniciados em 2000 - 2003, o que mostra uma ineficiência nessa área, visto que o dano não é compensado ${ }^{43}$. 0 TAC influencia a baixa eficácia da aplicação da lei, onde reduz o valor arrecadado em troca do compromisso de reparar o dano ${ }^{44}$.

As penas pecuniárias quando impostas, parecem ser insuficientes para indenizar o dano causado pelo ato ilícito e/ou, para agir como preventivo ao cometimento aos crimes ambientais $^{45}$.

As ACP's foram instauradas pelo motivo de que o autuado não compareceu ou não foi encontrado e os IC's foram instaurados para identificar a autoria e/ou aprofundar mais as informações e os danos ambientais causados. Esses procedimentos são encaminhados ao Poder Judiciário, onde não possuem uma vara especifica ambiental e se juntam com os demais tipos de crimes e aguardam o andamento e conclusão.

Uma questão que pouco se discute no Ministério Público Estadual, bem como, em outros órgãos de proteção ambiental, são formas de proteção da fauna. 0 baixo índice de ocorrência não significa que não há registro de crimes ambientais contra a fauna. Apenas uma comodidade

\footnotetext{
${ }^{43}$ BRITO, B.; BARRETO, P. Sugestões para a aplicação da Lei de Crimes Ambientais no setor florestal da Amazônia. Revista de Direitos Difusos, Ano VI, V. 30, 2005.

${ }^{44}$ MANCINI, P. F.; COIMBRA, M. A eficácia da aplicação da Lei de Crimes Ambientais.

${ }^{45}$ AKELLA, A. S.; ORLANDO, H.; ARAÚJO, M.; CANNON, J. B. O fortalecimento da defesa contra crimes ambientais: análise econômica do sistema de implementação legal na Mata Atlântica do Brasil. Megadiversidade. V. 2. $\mathrm{n}^{\circ}$ 1-2, 2006.
} 
em apurar crimes contra a flora, onde a maioria das ocorrências está relacionada com madeiras serradas e desmatamentos.

Os crimes contra a fauna requer uma maior logística, onde, desde o momento da apreensão, devem-se analisar os cuidados necessários no transporte e alimentação até o CETAS mais próximo, onde este pode ficar a mais de $200 \mathrm{~km}$ de distância do local da apreensão. Além disso, há a necessidade de profissionais e equipamentos para captura e transporte de acordo ao animal.

Deve-se levar em conta a importância que a fauna no seu ambiente natural e suas interações com a flora, onde muitos desses animais são dispersores de sementes ou quebra das dormências das sementes, onde, retirando esse animal do meio ambiente natural, pode-se estar condenando uma determinada espécie da flora.

Várias medidas estão sendo tomadas para acelerar os processos no Judiciário na região norte do país, como a virtualização dos processos, videoconferências, cooperação com outros órgãos e a criação de varas ambientais ${ }^{46}$.

\section{CONCLUSÃO}

O presente estudo mostrou que há a necessidade de criar iniciativas para responsabilizar os infratores e coibir ou diminuir os crimes ambientais no Litoral Sul da Bahia, com a localização e identificação dos crimes e seus responsáveis, bem como, uma maior agilidade nos processos administrativos, civis e penais, para punir os infratores e aumentar a eficácia, eficiência e efetividades dos órgãos ambientais e das Leis de Crimes Ambientais.

Vários fatores contribuem para a ineficiência na apuração dos crimes ambientais no Litoral Sul da Bahia. Assim, podemos organizar em tópicos os principais problemas encontrados, como, os processos administrativos, identificação dos crimes e os procedimentos civil e penal.

Para os procedimentos administrativos, o ideal seria um número maior de fiscais, aquisição e uso de equipamentos de sensoriamento remoto, recursos e parceria com outros órgãos de fiscalização (estadual e municipal), aumentaria o nível de detecção dos crimes ambientais no Litoral Sul da Bahia. Além disso, uma maior agilidade na apuração dos processos administrativos diminuiria a sensação de impunidade, pois, resoluções, normas, decretos e legislações, todos na esfera ambiental, já possuímos.

${ }^{46}$ BRITO, B.; BARRETO, P. A eficácia da aplicação da Lei de Crimes Ambientais pelo IBAMA para a proteção de florestas no Pará. 
Uma forma de aumentar o número de fiscais no Litoral Sul da Bahia e nas demais áreas do Estado, seria a aplicação do convênio com a Polícia Militar da Bahia para o exercício do poder de polícia administrativo ambiental, como prevê o Art. 175-A, Parágrafo Único e o Art. 176-B, Parágrafo Único, da Lei Estadual ${ }^{47}$. Com isso, mais efetividade na aplicação e fiscalização da Lei de Crimes Ambientais.

Da mesma forma que acontece com o IBAMA, às infrações imposta pelos órgãos de fiscalização ambiental do Estado e/ou pelo Município, uma cópia do auto de infração deveria ser encaminhado ao Ministério Público para apuração do crime na esfera civil e penal.

Um avanço importante no andamento dos processos administrativos seria a virtualização, onde as informações se deslocariam entre as unidades e os setores do IBAMA mais rapidamente e evitaria perda de tempo e recursos no deslocamento dos processos, bem como, o autuado poderia acompanhar o andamento do Processo Administrativo, os recursos entregues e as sanções administrativas impostas. Essa virtualização também nos processos administrativos abertos pelos Estados e Municípios.

Outro avanço importante seria a integração dos órgãos ambientais, onde os autos de infrações e demais sanções administrativas, seja na esfera Federal, Estadual ou Municipal, em propriedades localizadas na zona rural, onde estes autos deverão estar vinculados ao Cadastro Ambiental Rural - CAR, onde não poderia vender a propriedade, solicitar empréstimos ou benefícios do Governo Federal, Estadual ou Municipal enquanto houvesse alguma pendência, como acontece no Sistema Nacional de Trânsito, onde a multa entra no cadastro do veículo e o mesmo não pode licenciar no ano seguinte sem a devida quitação e o condutor é penalizado com pontos em sua habilitação.

$O \mathrm{CAR}^{48}$ foi criado para o registro eletrônico das propriedades rurais em todo o país, com a finalidade de integrar as informações ambientais das propriedades e posses rurais, entre outras funções, para o planejamento ambiental e o combate ao desmatamento.

Com base no CAR, todo auto de infração será cadastrado no sistema e vinculado à propriedade e o proprietário, onde o agente/fiscal terá acesso às informações necessárias para elaborar o auto de infração e demais atos administrativos (Federal, Estadual ou Municipal), onde esse registro ficará no sistema até a sua resolução. Além disso, qualquer pessoa terá acesso a essas informações quando for adquirir um imóvel rural ou solicitar algum tipo de serviço ou beneficio nessa propriedade.

${ }^{47}$ LEI No 12.377 , de 28 de dezembro de 2011.

${ }^{48}$ Decreto $^{\circ}{ }^{\circ} 7.830$, de 17 de outubro de 2012. 
Da mesma forma, em empresas devidamente cadastradas, as informações serão cadastradas e vinculadas no CTF, CNPJ e IPTU; e nas pessoas físicas no CPF, onde estes deverão ficar vinculadas até o término ou suspensão da dívida durante o andamento do Processo Administrativo. Nesse caso, as empresas terão que solucionar o problema até a renovação do alvará de funcionamento, entre outros.

A Lei Complementar ${ }^{49}$ fixa normas de cooperação entre a União, Estados e Municípios nas ações administrativas à proteção do meio ambiente, nesse caso, segundo o Art. 9, XIII, o município deverá exercer o controle e fiscalizar as atividades e empresas potencialmente poluidoras.

Com isso, um fortalecimento dos órgãos estaduais e municipais, onde a Secretaria de Meio Ambiente do Estado da Bahia - SEMA, juntamente com seu órgão de fiscalização e licenciamento, o Instituto do Meio ambiente - IMA e a Secretaria de Meio Ambiente e Urbanismo - SEMAU de Ilhéus, onde, através da virtualização dos processos administrativos, seriam mais eficientes e transparentes na sua atividade.

Um portal da transparência para os processos de licenciamento e de autuações referentes aos crimes ambientais, em todas as esferas (Federal, Estadual e Municipal) aumentaria mais a fiscalização de toda a sociedade nas atividades ambientais e daria uma maior transparência no exercício da profissão, com isso, diminuiria a impunidade e apadrinhamento.

Para os procedimentos na área civil e penal, a criação de promotorias e varas especializadas em meio ambiente daria um grau maior de agilidade nos processos, onde todos seriam especializados e cientes da complexidade ambiental, com conhecimento jurídico e ambiental, sensível suficiente para entender a gravidade jurídica da aplicação das normas ambientais ${ }^{50}$.

Apesar dos números apontarem uma ineficiência na apuração dos crimes contra a fauna por diversos motivos, essa situação deve ser revista pelos órgãos ambientais, uma vez que, é muito importante a fauna em seu ambiente natural e suas relações com a flora, como também, da quantidade de animais que estão entrando na lista de extinção.

Os reflexos da dificuldade em se trabalhar com fauna silvestre, não pode simplesmente o agente fiscalizador recolher o animal em residências e soltá-lo em seguida, sem os devidos cuidados. Pois essa prática, sem a devida orientação de Biólogos e Veterinários, constitui uma

${ }^{49}$ LEI COMPLEMENTAR $\mathrm{N}^{\circ}$ 140, de 8 de dezembro de 2011.

${ }^{50}$ SANTOS, C. F. R. Lei de crimes ambientais e a existência de varas ambientais no contexto brasileiro. 
pena de morte para o animal que acabou de ser solto e/ou um desequilibro na fauna local. 0 que torna um desastre ambiental.

Os animais não podem ser soltos porque podem apresentar dificuldades em voar, dificuldades em achar/procurarem alimento e abrigo, doenças, habitat ou bioma errado, superpopulação no local, entre outros.

Uma solução a longo prazo seria a inserção de projetos de educação ambiental nas escolas em todos os níveis e ensino, com o propósito de educar e informar a importância da fauna em seu ambiente natural e dos perigos de se criar um animal silvestre em cativeiro, além disso, propagandas educativas também ajudariam a diminuir essa cultura de criar animal silvestre em cativeiro, bem como, o consumo de carnes e outras partes do animal.

0 maior problema enfrentado é a impunidade dos infratores, com isso, surge à sensação de que o crime compensa e o autor livre para cometer outros crimes.

\section{REFERÊNCIAS}

ATLAS, Atlas dos Remanescentes Florestais da Mata Atlântica, período 2010 - 2011. Fundação SOS Mata Atlântica e INPE. Portal SOS Mata Atlântica. Disponível em:

<http://www.sosmatatlantica.org.br/>. Disponível em: 09 jan. 2012.

ARAÚJO, M. et. al. A Mata Atlântica do Sul da Bahia: situação atual, ações e perspectivas. Série Estados e Regiões da RBMA, Caderno 8. São Paulo, 1998. Disponível em:

<http://www.rbma.org.br/rbma/pdf/Caderno_08.pdf>. Acesso em: 31 jul. 2012.

ALIANCA. Aliança para a Conservação da Mata Atlântica. Disponível em:

<http: //www.aliancamataatlantica.org.br/?p=2>. Acesso em 20 jan. 2012.

AKELLA, A. S.; ORLANDO, H.; ARAÚJO, M.; CANNON, J. B. O fortalecimento da defesa contra crimes ambientais: análise econômica do sistema de implementação legal na Mata Atlântica do Brasil. Megadiversidade. V. 2. $\mathrm{n}^{\circ}$ 1-2, 2006.

BRITO, B.; BARRETO, P. Sugestões para a aplicação da Lei de Crimes Ambientais no setor florestal da Amazônia. Revista de Direitos Difusos, Ano VI, V. 30, 2005.

BRITO, B.; BARRETO, P. A eficácia da aplicação da Lei de Crimes Ambientais pelo IBAMA para a proteção de florestas no Pará. Disponível em: <http://www.imazon.org.br/publicacoes/artigoscientificos/a-eficacia-da-aplicacao-da-lei-de-crimes>. Acesso em: 15 jan. 2012.

DAL VESCO, L. L. Culturas nodulares e micropropagação de bromélias nativas da mata atlântica (Billbergia zebrina e Vriesea reitzii): bases para a conservação e propagação massal. Tese. Universidade Federal de Santa Catarina. Florianópolis, 2010. 91 p. 
DECRETO $\mathrm{N}^{\circ}$ 6.514, de 22 de junho de 2008. Dispõe sobre as infrações e sanções administrativas ao meio ambiente, estabelece o Processo Administrativo federal para apuração destas infrações, e dá outras providências. Disponível em: <http://www.planalto.gov.br/ccivil_03/_ato20072010/2008/decreto/D6514.htm>. Acesso em: 10 jan. 2012.

DECRETO $N^{\circ} 7.830$, de 17 de outubro de 2012. Dispõe sobre o Sistema de Cadastro Ambiental Rural, o Cadastro Ambiental Rural, estabelece normas de caráter geral aos Programas de Regularização Ambiental, de que trata a Lei $\mathrm{n}^{\circ}$ 12.651, de 25 de maio de 2012, e dá outras providências. Acesso em: <http://www.planalto.gov.br/ccivil_03/_Ato20112014/2012/Decreto/D7830.htm>. Acesso em: 07 jul. 2012.

DECRETO-LEI $\mathrm{n}^{\circ}$ 2.848, de 7 de dezembro de 1940. Código Penal. Disponível em: <http://www.planalto.gov.br/ccivil_03/decreto-lei/del2848.htm>. Acesso em: 17 jan. 2012.

FARIA, D. A fauna na paisagem cacaueira do Sul da Bahia. Disponível em: <http://www.museugoeldi.br/sobre/NOTICIAS/pdf_apresentacoes_simposio/DeborahFaria.pdf>. Acesso em: 15 jan. 2012.

FUNDAÇÃO SOS MATA ATLÂNTICA. Portal SOS Mata Atlântica. Disponível em: <http://www.sosmatatlantica.org.br/>. Disponível em: 09 jan. 2012.

IBGE. Instituto Brasileiro de Geografia e Estatística. Disponível em: <http: //www.ibge.gov.br>. Acesso em: 22 de fev. 2012.

IN 10. Instrução Normativa IBAMA ${ }^{\circ} 10$, de 7 de dezembro de 2012. Publicada no Diário Oficial da União em 10 de dezembro de 2012.

LEI COMPLEMENTAR $N^{\circ}$ 140, de 8 de dezembro de 2011. Fixa normas, nos termos dos incisos III, VI e VII do caput e do parágrafo único do art. 23 da Constituição Federal, para a cooperação entre a União, os Estados, o Distrito Federal e os Municípios nas ações administrativas decorrentes do exercício da competência comum relativas à proteção das paisagens naturais notáveis, à proteção do meio ambiente, ao combate à poluição em qualquer de suas formas e à preservação das florestas, da fauna e da flora; e altera a Lei no 6.938, de 31 de agosto de 1981 . Disponível em: < http://www.planalto.gov.br/ccivil_03/leis/lcp/Lcp140.htm>. Acesso em: 03 fev. 2012.

LEI N 9.503, de 23 de setembro de 1997. Instituí o Código de Trânsito Brasileiro. Disponível em: <http://www.planalto.gov.br/ccivil_03/leis/L9503.htm>. Acesso em: 03 fev. 2012.

LEI N ${ }^{\circ}$ 9.605, de 12 de fevereiro de 1998. Dispõe sobre as sanções penais e administrativas derivadas de condutas e atividades lesivas ao meio ambiente, e dá outras providências. Disponível em: <http://www.planalto.gov.br/ccivil_03/leis/L9605.htm>. Acesso em: 03 fev. 2012. 
LEI No 12.377, de 28 de dezembro de 2011. Altera a Lei $n^{\circ} 10.431$, de 20 de dezembro de 2006, que dispõe sobre a Política Estadual de Meio Ambiente e de Proteção à Biodiversidade, a Lei $n^{\circ}$ 11.612, de 08 de outubro de 2009, que dispõe sobre a Política Estadual de Recursos Hídricos e a Lei $n^{\circ} 11.051$, de 06 de junho de 2008, que Reestrutura o Grupo Ocupacional Fiscalização e Regulação. Disponível em: <http://www.seia.ba.gov.br/legislacao-ambiental/leis/lei-n-12377de-28-de-dezembro-de-2011>. Acesso em: 06 fev. 2012.

MANCINI, P. F.; COIMBRA, M. A eficácia da aplicação da Lei de Crimes Ambientais. Disponível em: <http://intertemas.unitoledo.br/revista/index.php/ETIC/article/viewFile/1721/1640>. Acesso em: 15 jan. 2012.

MMA Ministério do Meio Ambiente, Mata Atlântica: patrimônio nacional dos brasileiros. Secretaria de Biodiversidade e Florestas. Núcleo Mata Atlântica e Pampa; organizadores Maura Campanili [e] Wigold Bertoldo Schaffer. - Brasília, 2010.

MYERS, N.; MITTERMEIER, R.A.; MITTERMEIER, C.G.; FONSECA, G.A.B. \& KENT, J. 2000. Biodiversity hotspots for conservation priorities. Nature 403: 853-858.

MPNUMA. Ministério Público da Bahia: Núcleo da Mata Atlântica. Disponível em: <http://mpnuma.ba.gov.br/>. Acesso em: 12 jan. 2012.

RENCTAS. Rede Nacional de Combate ao Tráfico de Animais Silvestres. $1^{\circ}$ Relatório Nacional sobre o Tráfico de Fauna Silvestre. Disponível em: <http://www.renctas.org.br/pt/home/>. Acesso em: 20 jan. 2012.

RIBEIRO, M.C., METZGER, J.P., MARTENSEN, A.C., PONZONI, F.J. \& HIROTA, M.M. 2009. The Brazilian Atlantic Forest: how much is left, and how is the remaining forest distributed? Implications for conservation. Biol. Conserv. 142:1141-1153.

SANTOS, C. F. R. Lei de crimes ambientais e a existência de varas ambientais no contexto brasileiro. Disponível em: <http://www. anppas.org.br/encontro4/cd/ARQUIVOS/GT6-395-36220080510235039.pdf>. Acesso em: 21 jan. 2012.

SEl. Superintendência de Estudos Sociais e Econômicos. Disponível em: <http://www.sei.ba.gov.br/>. Acesso em: 07 jan. 2012.

TCU. Tribunal de Contas da União. TC 022.631/2009-0. Disponível em: <http://www.tcu.gov.br/Consultas/Juris/Docs/CONSES/TCU_ATA_0_N_2012_7.pdf>. Acesso em: 13 jan. 2012.

Recebido em: 05.09.2013

Correções em: 19.11.2013

Aprovado em: 29.12.2013 